\title{
The Cycle of Kinetochore-Negative Micronuclei and Chromosome Fragments Occurred in Mitosis of Hela Cells
}

Xiuhong Zhou' ${ }^{1}$, Daxiang $\mathrm{Li}^{1}$, Zhongwen $\mathrm{Xie}^{1 *}$, Erkang Jiang ${ }^{1,2^{*}}$, Lianping $\mathrm{Wei}^{2}$, Fang $\mathrm{TaO}^{2}$, Mei $\mathrm{Yu}^{2}$ and Shu Wang ${ }^{2}$

${ }^{1}$ State Key Laboratory of Tea Plant Biology and Utilization, Anhui Agriculture University, Hefei, Anhui, P.R. China

${ }^{2}$ School of Life Sciences, Anhui Agriculture University, Hefei, Anhui, P.R.China.

\begin{abstract}
Objective: Micronuclei (MNi) are extensively used to evaluate genotoxic effects and chromosome instability. According to the presence of kinetochores or not, $\mathrm{MNi}$ are further classified into kinetochore-negative $\mathrm{MNi}(\mathrm{K}-\mathrm{MNi})$ and kinetochore-positive $\mathrm{MNi}(\mathrm{K}+\mathrm{MNi})$, which show the different mechanisms of micronucleus formation. However, the differences in fates of $\mathrm{K}-\mathrm{MNi}$ and $\mathrm{K}+\mathrm{MNi}$ have not been completely addressed. The present study aims to address these questions.
\end{abstract}

Methods: Here, HeLa CENP B-GFP H2B-mCherry cells were chosen to distinguish $\mathrm{K}^{+} \mathrm{MNi}$ and $\mathrm{K}^{-} \mathrm{MNi}$ in living cells. In the cells, MNi were identified by H2B-mCherry and further classified into $\mathrm{K}^{+} \mathrm{MNi}$ and $\mathrm{K}^{-} \mathrm{MNi}$, i.e. the $\mathrm{K}^{+} \mathrm{MNi}$ contained CENP B-GFP, while the $\mathrm{K}^{-} \mathrm{MNi}$ did not. Long-term live-cell imaging was applied in the cells to record the dynamics of cell mitosis, especially $\mathrm{K}^{+} \mathrm{MNi}$ and $\mathrm{K}^{-} \mathrm{MNi}$.

Results: Our results show that the presence of $\mathrm{K}^{-} \mathrm{MN}$ or $\mathrm{K}^{+} \mathrm{MN}$ did not result in multipolar mitosis. $\mathrm{K}^{-} \mathrm{MN}$-bearing cells produced much more chromosome fragments than did MN-free cells. Most of the chromosome fragments eventually merged into $\mathrm{K}^{-} \mathrm{MNi}$. $\mathrm{K}^{+} \mathrm{MN}$-bearing cells yielded more kinetochore-positive lagging chromosomes $\left(\mathrm{K}^{+} \mathrm{LCs}\right)$ and $\mathrm{K}^{+} \mathrm{MNi}$ than $\mathrm{MN}$-free cells did.

Conclusion: The results suggested the differences in the fates of $\mathrm{K}^{+} \mathrm{MNi}$ and $\mathrm{K}^{-} \mathrm{MNi}$ in mitosis. The cycle of $\mathrm{K}^{-}$ $\mathrm{MN} \rightarrow$ Chromosome fragment $\rightarrow \mathrm{K}-\mathrm{MN}$ may occur in generations of $\mathrm{K}^{-} \mathrm{MN}$-bearing cells, while part of $\mathrm{K}^{+} \mathrm{MNi}$ might reincorporate into the main nucleus.

Keywords: Chromosome fragment; Kinetochore; Live cell imaging; Micronucleus; Mitosis

Abbreviations: $\mathrm{MN}$ : Micronucleus; MNi: Micronuclei; K-MN Kinetochore-Negative Micronucleus; $\mathrm{K}^{+} \mathrm{MN}$, kinetochore-positive micronucleus; DC: Displaced Chromosome; $\mathrm{K}^{+} \mathrm{DC}$, kinetochorePositive Displaced Chromosome; LC: Lagging Chromosome; $\mathrm{K}^{+} \mathrm{LC}$ : kinetochore-Positive Lagging Chromosome; CB: Chromosome Bridge.

\section{Introduction}

The micronucleus (MN) test determines chromosomal level DNA damage and is widely used to biomonitor humans exposed to clastogens and aneugens $[1,2]$. Elevated frequencies of $\mathrm{MNi}$ are also found in patients with cancer and other diseases [3,4]. MNi are formed from an entire chromosome or from a chromosomal fragment. The kinetochore is an essential structure composed of a number of conserved protein complexes on the centromere in eukaryotes. It serves as a bridge between the spindle microtubules and chromosomes and regulates chromosome segregation [5,6]. Based on the presence of kinetochores, $\mathrm{MNi}$ are further classified into $\mathrm{K}^{+} \mathrm{MNi}$ and $\mathrm{K}^{-} \mathrm{MNi}$. In fixed cells, kinetochores in $\mathrm{MNi}$ can be detected by immunofluorescent staining using anti-kinetochore antibodies from the serum of scleroderma (CREST syndrome) patients. Aneugenic agents mainly induce $\mathrm{K}^{+} \mathrm{MNi}$ in human cells, while clastogenic agents enhance $\mathrm{K}^{-} \mathrm{MNi}$. The classification increases the specificity of the MN test [7-11].

In live cells, kinetochores in $\mathrm{MNi}$ were identified in a dual-colour fluorescent cell line, HeLa CENP B-GFP H2B-Cherry cells [12]. In these cells, chromosomes and kinetochores were labelled by H2B-m Cherry and CENP B-GFP, respectively. MNi were marked by H2B-m Cherry. $\mathrm{K}^{+} \mathrm{MNi}$ were identified by CENP B-GFP, while $\mathrm{K}^{-} \mathrm{MNi}$ did not have the GFP signal. The differences in the origins of $\mathrm{K}^{+} \mathrm{MNi}$ and
$\mathrm{K}^{-} \mathrm{MNi}$ were investigated using this construction [12]. However, the fates of $\mathrm{K}^{+} \mathrm{MNi}$ and $\mathrm{K}^{-} \mathrm{MNi}$ in the mitosis of HeLa cells have not been completely addressed.

Dynamic MN formation was analysed in several types of living cells [13-15]. The MN-bearing cells frequently produced daughter cells with MNi through chromosome lagging during cell division [16] $\mathrm{MNi}$ were partly reincorporated into daughter nuclei after mitosis [17]. If this is the case, there should be significant differences between cells with $\mathrm{K}^{+} \mathrm{MNi}$ and $\mathrm{K}^{-} \mathrm{MNi}$, because $\mathrm{K}^{+} \mathrm{MNi}$ contain kinetochore structures and $\mathrm{K}^{-} \mathrm{MNi}$ not. When $\mathrm{K}+\mathrm{MN}$-bearing cells enter mitosis, the chromosomes from $\mathrm{K}^{+} \mathrm{MNi}$ may be indistinguishable from those of the main nucleus and might resume normal biological activity. While $\mathrm{K}^{-} \mathrm{MN}$-bearing cells enter mitosis, the chromosomal fragments in $\mathrm{K}^{-} \mathrm{MNi}$ cannot be caught by spindle microtubules because they do not have functional kinetochores and subsequently fail to be pulled onto the metaphase plate. Chromosomal material from $\mathrm{K}^{-} \mathrm{MNi}$ may condense into chromosome fragments in meta-anaphase and might reform as $\mathrm{K}^{-} \mathrm{MNi}$ in daughter cells. In other words, $\mathrm{K}^{-} \mathrm{MN}$-bearing cells may produce more chromosome fragments and $\mathrm{K}^{-} \mathrm{MNi}$ than do $\mathrm{MN}$ free cells during mitosis. $\mathrm{K}^{+} \mathrm{MN}$-bearing cells might form more $\mathrm{K}^{+} \mathrm{LCs}$

${ }^{*}$ Corresponding author: Xie Z and Jiang E, State Key Laboratory of Tea Plan Biology and Utilization, Anhui Agriculture University, Hefei, Anhui, 230036, P.R.China, Tel:+(86) 10-82865135 E-mail: zhongwenxie@ahau.edu.cn

Received May 11, 2018; Accepted May 23, 2018; Published June 05, 2018

Citation: Zhou X, Li D, Xie Z, Jiang E, Wei L, et al. (2018) The Cycle of KinetochoreNegative Micronuclei and Chromosome Fragments Occurred in Mitosis of Hela Cells. Single Cell Biol 7: 172. doi:10.4172/2168-9431.1000172

Copyright: ( $) 2018$ Zhou X, et al. This is an open-access article distributed unde the terms of the Creative Commons Attribution License, which permits unrestricted use, distribution, and reproduction in any medium, provided the original author and source are credited. 
and $\mathrm{K}^{+} \mathrm{MNi}$ during cell division but to a lesser extent, because some of the chromosomes from $\mathrm{K}^{+} \mathrm{MNi}$ may reincorporate in the main nucleus.

To test this possibility, multi-layer high-resolution imaging was conducted by using HeLa CENP B-GFP H2B-m Cherry cells. The dynamics of mitosis in $\mathrm{K}^{+} \mathrm{MN}$ - and $\mathrm{K}^{-} \mathrm{MN}$-bearing cells were accurately recorded over short intervals during mitosis. The fates of $\mathrm{K}^{-} \mathrm{MNi}$ and $\mathrm{K}^{+} \mathrm{MNi}$ in mitosis were investigated by reverse examination of these time-lapse records.

\section{Materials and Methods}

\section{Cell culture}

HeLa CENP B-GFP H2B-mCherry dual-colour fluorescent cells were constructed in our laboratory [12] and cultured in DMEM supplemented with $10 \%$ foetal calf serum, $1 \%$ non-essential amino acids and antibiotics $(100 \mathrm{U} / \mathrm{mL}$ penicillin and $100 \mathrm{U} / \mathrm{mL}$ streptomycin). These regents were purchased from GIBCO. The cell cultures were maintained at $37^{\circ} \mathrm{C}$ in a humidified atmosphere of $5 \% \mathrm{CO}_{2}$ and $95 \%$ air.

\section{Live cell imaging}

Live-cell imaging was performed as previously described [12]. HeLa CENP B-GFP H2B-mCherry cells were grown on gridded coverglass bottom dishes (MatTek, Cat.P35G-1.5-7-C-grid) at a density of $2 \times 10^{5}$ cells per dish for $26 \mathrm{~h}$. Images were then automatically acquired at multiple locations on the cover-slip using a Nikon TE2000E inverted microscope fitted with a $60 \times$ Nikon Plan Fluor objective, a linearly encoded stage (Proscan, Prior) and a Hamamatsu Orca-ER CCD camera. Fluorescence illumination was implemented using a mercury-arc lamp with two neutral density filters (for a 32 -fold reduction in intensity). The microscope was controlled using Simple PCI (Compix) software and housed in a custom-designed $37^{\circ} \mathrm{C}$ chamber with a secondary internal chamber that delivered humidified 5\% CO2. Fluorescence and differential interference contrast images were obtained every $10 \mathrm{~min}$ for 24-48 hrs. Autofocusing was performed every 90 min using the fluorescence channel.

\section{Analysis of the live cell images}

The image series were obtained from the live cell imaging experiments and then converted into movies using the Metamorph software (Universal Imaging Corporation, USA). The following criteria were applied to distinguish the abnormal chromosomes and mitoses during the scoring.

MNi: The definition of $\mathrm{MNi}$ was the same as described in a previous study [12]. MNi were individually identified in each cell as an extra-nuclear mCherry-positive body with a size less than $1 / 3 \mathrm{rd}$ of the mainnucleus and with similar fluorescence intensity to that of the main nucleus. MNi were identified by $\mathrm{H} 2 \mathrm{~B}$-mCherry signals. A $\mathrm{K}^{+} \mathrm{MN}$ showed a CENP B-GFP signal as well as $\mathrm{H} 2 \mathrm{~B}-\mathrm{mCherry}$, while a $\mathrm{K}^{-} \mathrm{MN}$ showed only the H2B-mCherry signal.

Abnormal chromosomes: Chromosomes carry both H2B-mCherry and CENP B-GFP signals in HeLa CENP B-GFP H2B-mCherry cells. Several abnormal chromosomes are defined as following.

Chromosome fragments: Chromosome fragments are kinetochore-negative pieces of chromosomes, which contain only $\mathrm{H} 2 \mathrm{~B}$ mCherry signals, but no CENP B-GFP.

Kinetochore-positive displaced chromosomes $(\mathrm{K}+\mathrm{DCs}): \mathrm{K}^{+} \mathrm{DCs}$ were identified as incorrectly aligned chromosomes that were observed outside of the equatorial plate during metaphase, which carry both H2B-mCherry and CENP B-GFP signals.

Kinetochore-positive Lagging chromosomes $(\mathrm{K}+\mathrm{LCs})$ : $\mathrm{K}+\mathrm{LCs}$ were identified as chromosomes that were observed in the mid zone during anaphase in mitosis, which carry both H2B-mCherry and CENP B-GFP signals.

Chromosome bridges (CBs): CBs were abnormal chromosomes that connected the two clusters of segregated chromosomes during anaphase or telophase. CBs were identified using H2B-mCherry signals, regardless of the CENP B-GFP signals.

Bipolar mitoses: Bipolar mitoses indicate those with metaphase equatorial plates oriented in two directions.

Multipolar mitoses: Multipolar mitoses mean those with metaphase equatorial plates oriented in three or more directions.

Statistical analysis: The data were analyzed using the $2 \times 2$ chisquare test of Origin Software (OriginLab Corporation). A p-value of less than 0.05 was considered statistically significant, and a $\mathrm{p}$-value of less than 0.001 was considered highly significant.

\section{Result}

In the present study, a total of 2,359 HeLa cells were scored by examining long-term real-time images, which included initial MNfree mononuclear cells (MN-free cells, $\mathrm{n}=556$ ), mononuclear cells each bearing a $\mathrm{K}^{-} \mathrm{MN}$ ( $\mathrm{K}^{-} \mathrm{MN}$-bearing cells, $\mathrm{n}=72$ ) and mononuclear cells each bearing a $\mathrm{K}^{+} \mathrm{MN}\left(\mathrm{K}^{+} \mathrm{MN}\right.$-bearing cells, $\mathrm{n}=57$ ) (Figure 1). After these cells entered mitosis, the dynamics of mitosis were recorded and analysed. The polar number of mitosis was compared among three types of cells: $\mathrm{MN}$-free, $\mathrm{K}^{-} \mathrm{MN}$-bearing and $\mathrm{K}^{+} \mathrm{MN}$-bearing cells. And we investigated the emergence and fate of abnormal chromosomes during mitosis in different type cells.

\section{Bipolar and multi-polar mitoses occurred in different type of cells}

During the course of time-lapse observation, we found that bipolar and multi-polar mitosis occurred in both $\mathrm{MN}$-bearing and $\mathrm{MN}$-free cells (Supplementary data Figure 1). The overwhelming majority of mitoses were bipolar rather than multi-polar (Figure 2). Bipolar mitosis was predisposed in the three types of cells with similar rates. The bipolar rates for $\mathrm{K}^{-} \mathrm{MN}$ - and $\mathrm{K}^{+} \mathrm{MN}$-bearing cells and $\mathrm{MN}$-free cells were $99.3 \pm$ $0.983 \%, 99.12 \pm 1.24 \%, 99.64 \pm 0.0429 \%$, respectively. The frequencies of multi-polar mitosis in mono-nucleated cells were very low in $\mathrm{MN}$ free cells $(0.362 \pm 0.0405 \%)$ and in $\mathrm{K}^{-} \mathrm{MN}$ - or $\mathrm{K}^{+} \mathrm{MN}$-bearing cells $(0.695 \pm 0.57 \%$ or $0.877 \pm 0.655 \%)$, while most mitoses in bi-nucleated cells were multi-polar (data not shown). The results suggested that the presence of $\mathrm{K}^{-} \mathrm{MNi}$ and $\mathrm{K}^{+} \mathrm{MNi}$ did not increase multi-polar mitosis. $\mathrm{K}^{-}$ $\mathrm{MN}^{-}$and $\mathrm{K}^{+} \mathrm{MN}$ bearing cells were inclined to bipolar mitosis, as were MN-free cells.

\section{Emergence of abnormal chromosomes in different type cells}

In this study, the dynamics of abnormal chromosomes were observed through live-cell imaging in HeLa cells. Abnormal chromosomes that emerged during mitosis were classified by CENP B-GFP signals. Chromosomal materials possess H2B-mCherry signals. Chromosome fragments carry only $\mathrm{H} 2 \mathrm{~B}$-mCherry signals, but no CENP B-GFP. $\mathrm{K}^{+} \mathrm{DCs}$ and $\mathrm{K}^{+} \mathrm{LCs}$ contain both $\mathrm{H} 2 \mathrm{~B}-\mathrm{mCherry}$ and CENP B-GFP signals.

The K-MN-bearing cells produced higher frequencies of 
Citation: Zhou X, Li D, Xie Z, Jiang E, Wei L, et al. (2018) The Cycle of Kinetochore-Negative Micronuclei and Chromosome Fragments Occurred in Mitosis of Hela Cells. Single Cell Biol 7: 172. doi:10.4172/2168-9431.1000172
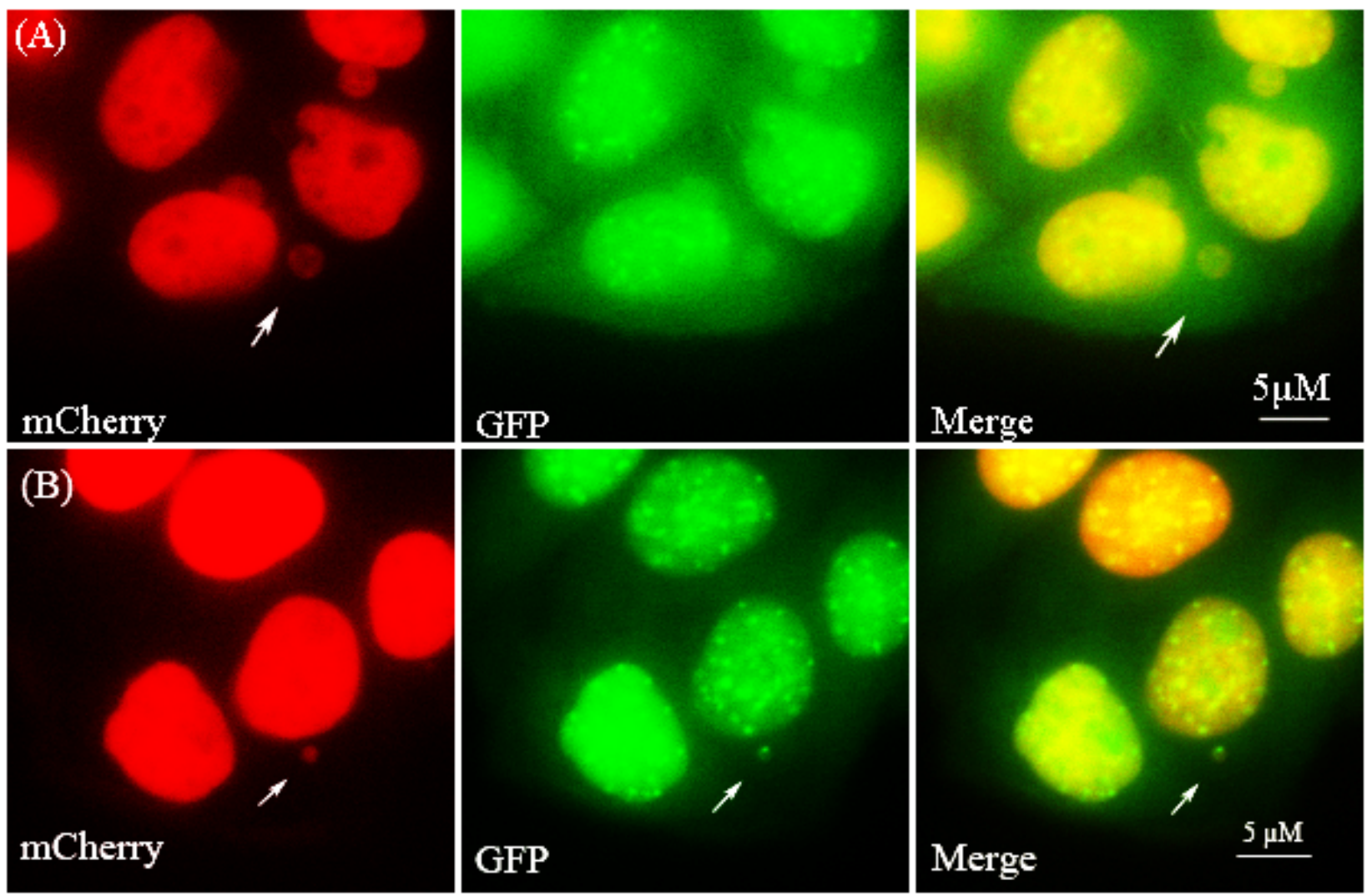

Figure 1: Representative figures showed a K-MN and a K+MN in HeLa CENP B-GFP H2B-mCherry cells. In the dual-color fluorescent cell line, micronuclei (MNi) were labeled by $\mathrm{H} 2 \mathrm{~B}-\mathrm{mCherry}$. A K+MN carried a CENP B-GFP signal, while $\mathrm{K}^{-} \mathrm{MN}$ did not. Selected serial images (including mCherry, GFP and merged images) from time-lapse records show examples of: (A). A representative figure of a $\mathrm{K}^{-} \mathrm{MN}$. An arrow points to a $\mathrm{K}-\mathrm{MN}$ carrying the $\mathrm{mCherry}$ signal. (B). A representative figure of a $\mathrm{K}^{+} \mathrm{MN}$. An arrow points to a $\mathrm{K}+\mathrm{MN}$ carrying both $\mathrm{mCherry}$ and GFP signals.

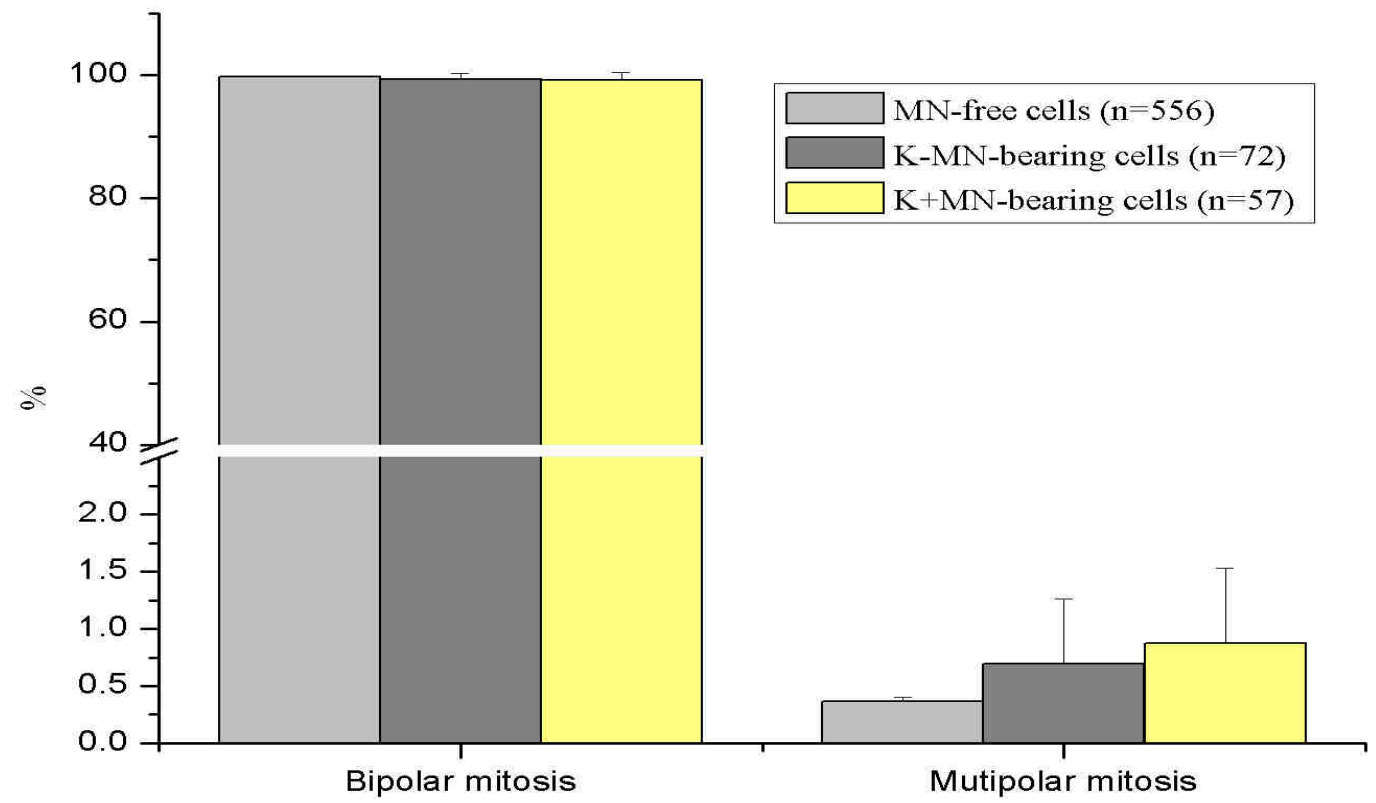

Figure 2: Bipolar and multi-polar mitoses occurred in different types of cells. Both bipolar and multi-polar mitosis occurred in MN-bearing and MN-free HeLa CENP $\mathrm{B}-\mathrm{GFP}$ H2B-mCherry cells. Most mitoses were bipolar rather than multi-polar. There were no significant differences in the polar number of mitosis in MN-free, K$\mathrm{MN}$ - and $\mathrm{K}^{+} \mathrm{MN}$-bearing cells. 
Citation: Zhou X, Li D, Xie Z, Jiang E, Wei L, et al. (2018) The Cycle of Kinetochore-Negative Micronuclei and Chromosome Fragments Occurred in Mitosis of Hela Cells. Single Cell Biol 7: 172. doi:10.4172/2168-9431.1000172

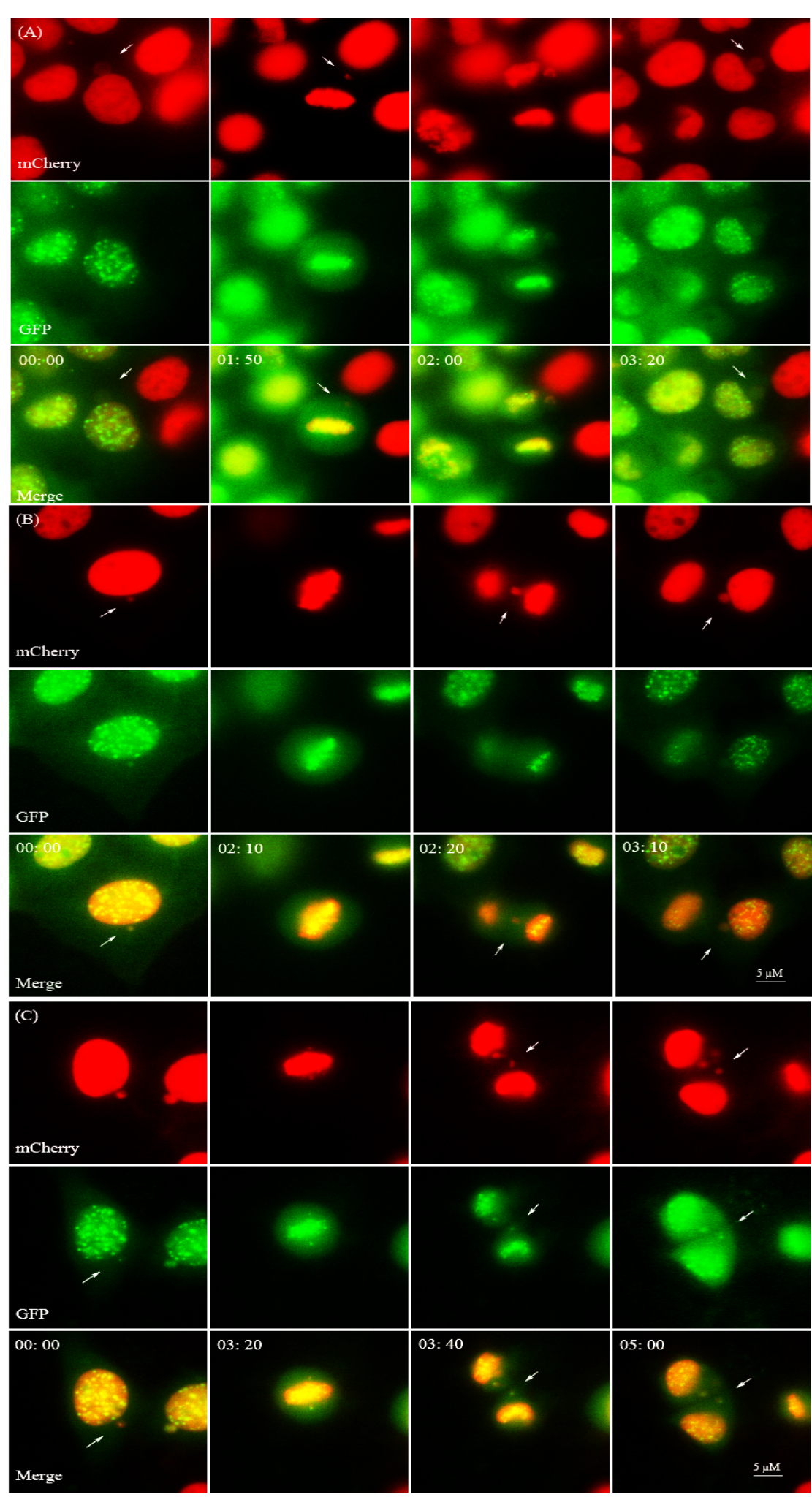

Figure 3: Representative figures of special abnormal chromosomes that frequently emerged during mitoses of $\mathrm{K}^{-} \mathrm{MN}$-bearing and $\mathrm{K}^{+} \mathrm{MN}$-bearing cells. In the HeLa CENP B-GFP H2B-mCherry cells, selected serial images (including mCherry, GFP and merged images) from time-lapse records show examples of: (A). A K-MNbearing cell produced a chromosome fragment during metaphase and a $\mathrm{K}^{-} \mathrm{MN}$ in a daughter cell. Arrows points to a mother cell, a chromosome fragment and a K-MN, sequentially. (B). A K-MN-bearing cell produced a chromosome fragment during anaphase and a $\mathrm{K}^{-} \mathrm{MN}$ in a daughter cell. Arrows points to a mother cell, a chromosome fragment and a $\mathrm{K}^{-} \mathrm{MN}$, sequentially. (C). A $\mathrm{K}^{+} \mathrm{MN}$-bearing cell produced a $\mathrm{K}^{+} \mathrm{LC}$ during anaphase and a $\mathrm{K}^{-} \mathrm{MN}$ in a daughter cell. Arrows points to a mother cell, a $\mathrm{K}+\mathrm{LC}$ and a $\mathrm{K}+\mathrm{MN}$, sequentially. 
Citation: Zhou X, Li D, Xie Z, Jiang E, Wei L, et al. (2018) The Cycle of Kinetochore-Negative Micronuclei and Chromosome Fragments Occurred in Mitosis of Hela Cells. Single Cell Biol 7: 172. doi:10.4172/2168-9431.1000172
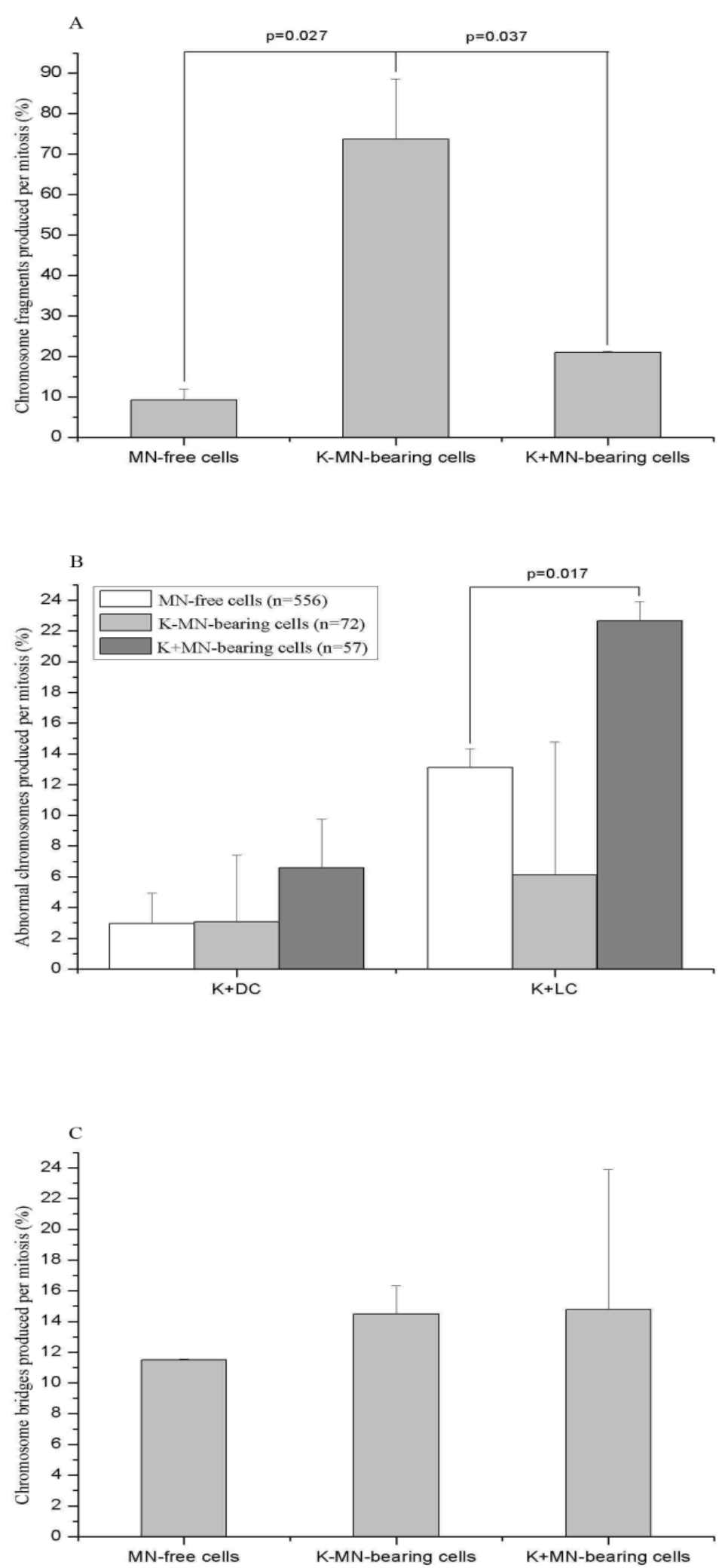

Figure 4: Frequencies of abnormal chromosomes were different emerged during mitosis of different HeLa cells. (A) Chromosome fragments produced during mitosis of HeLa CENP B-GFP H2B-mCherry cells. Chromosome fragments carried only H2B-mCherry signals, but no CENP B-GFP. Frequencies of chromosome fragments emerged were different during mitosis of different cells. (B) $K^{+} D C s$ and $K^{+L} C s$ produced during mitosis of HeLa CENP B-GFP H2B-mCherry cells. K+DCs and $\mathrm{K}+\mathrm{L} C$ s emerged in metaphase and anaphase respectively, and they carried both $\mathrm{H}_{2} \mathrm{~B}-\mathrm{m}$ Cherry and CENP $\mathrm{B}-\mathrm{GFP}$ signals. Frequencies of $\mathrm{K}+\mathrm{DCs}$ and $\mathrm{K}+\mathrm{LCs}$ emerged were different during mitosis of different cells. (C) Chromosome bridges produced during mitosis of HeLa CENP B-GFP H2B-mCherry cells. CBs were identified using H2B-mCherry signals, regardless of the CENP B-GFP status. Frequencies of CBs emerged were different during mitosis of different cells. 


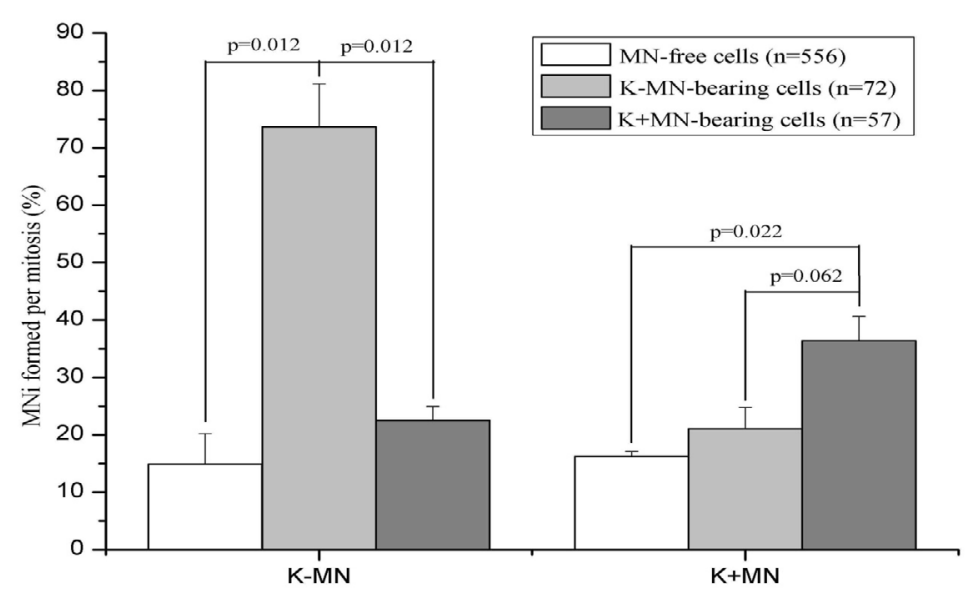

Figure 5: $\mathrm{K}^{-} \mathrm{MNi}$ and $\mathrm{K}^{+} \mathrm{MNi}$ were produced during the mitosis of HeLa CENP B-GFP H2B-mCherry cells. $\mathrm{K}+\mathrm{MNi}$ carried both $\mathrm{H} 2 \mathrm{~B}-\mathrm{mCherry}$ and $\mathrm{CENP} \mathrm{B}-\mathrm{GFP}$ signals. $\mathrm{K}^{-} \mathrm{MNi}$ contained only $\mathrm{H} 2 \mathrm{~B}-\mathrm{mCherry}$ signals, but no CENP B-GFP. Frequencies of $\mathrm{K}^{-} \mathrm{MNi}$ and $\mathrm{K}^{+} \mathrm{MNi}$ formed were different during mitosis of different cells.

chromosome fragments $(73.69 \pm 14.88 \%)$ than did MN-free cells $(9.16$ $\pm 2.75 \%)$; or $\mathrm{K}^{+} \mathrm{MN}$-bearing cells $(21.02 \pm 0.269 \%)$ during mitosis (Figures $3 \mathrm{~A}$ and $3 \mathrm{~B}$ and Figure $4 \mathrm{~A}$ ). The $\mathrm{K}^{+} \mathrm{MN}$-bearing cells yielded the higher frequency of $\mathrm{K}^{+} \mathrm{LC}(22.63 \pm 1.27 \%)$ than did $\mathrm{MN}$-free cells $(13.1 \pm 1.23 \%)$ during mitosis (Figures $3 \mathrm{C}$ and $4 \mathrm{~B}$ ).

Furthermore, CBs were identified using H2B-mCherry signals, regardless of the CENP B-GFP status. The MN-free cells exhibited a slightly lower frequency of $\mathrm{CB}(11.51 \pm 0.0566 \%)$ than did $\mathrm{K}^{-} \mathrm{MN}-$ bearing cells $(14.48 \pm 1.86 \%)$ or $\mathrm{K}+\mathrm{MN}$-bearing cells $(14.77 \pm 9.11 \%)$ during mitosis (Figure 4C), but did not reach significance. Different types of cells produced different abnormal chromosomes with different frequencies in mitosis.

\section{Formation of $\mathrm{K}-\mathrm{MN}$ and $\mathrm{K}+\mathrm{MN}$ in different cells}

The frequency of K-MN formation $(73.68 \pm 7.45 \%)$ during mitosis of $\mathrm{K}-\mathrm{MN}$-bearing cells was much higher than that of $\mathrm{MN}$-free cells $(14.92 \pm 5.27 \%)$ or $\mathrm{K}+\mathrm{MN}$-bearing cells $(22.54 \pm 2.41 \%)$ (Figure 5$)$. The frequency of $\mathrm{K}^{+} \mathrm{MN}$ formation in mitosis of $\mathrm{K}+\mathrm{MN}$-bearing cells (36.37 $\pm 4.29 \%)$ was significantly higher than that of $\mathrm{MN}$-free cells $(16.19 \pm$ $0.94 \%)$ or $\mathrm{K}-\mathrm{MN}$-bearing cells $(21.05 \pm 3.72 \%)$. Thus, $\mathrm{K}^{-} \mathrm{MN}$-bearing cells produced much more $\mathrm{K}^{-} \mathrm{MNi}$ in daughter cells than did $\mathrm{MN}$-free cells. Similarly, $\mathrm{K}^{+} \mathrm{MN}$-bearing cells generated more $\mathrm{K}^{+} \mathrm{MNi}$ in daughter cells than did $\mathrm{MN}$-free cells, but at a lower frequency.

\section{Discussion}

The MN test determines chromosomal level DNA damage and is widely used to biomonitor humans exposed to clastogens and aneugens $[1,2]$. Elevated frequencies of $\mathrm{MNi}$ are also found in patients with cancer and other diseases3, 4. Many inward and outward factors can induce $\mathrm{MN}$ formation. Regardless of the origin, $\mathrm{MNi}$ are usually stable in cells after formation14. Defects of MN structure affect basic nuclear functions, such as DNA repair and replication, resulting in massive damage in the chromatin of the MN. If MN chromatin is reincorporated in daughter cell nuclei, the damaged $\mathrm{MN}$ chromatin might contribute to genome instability. Thus, $\mathrm{MNi}$ are not only passive indicators of DNA damage but also active players in the formation of DNA lesions and genome instability $[17,18]$.

In a previous study by our laboratory, the emergence of abnormal nucleic structures was investigated using MN-free HeLa CENP B-GFP
H2B-mCherry cells [12]. $\mathrm{K}^{-} \mathrm{MNi}$ originate mainly from chromosome fragments and CBs. $\mathrm{K}^{+} \mathrm{MNi}$ derive predominantly from $\mathrm{K}^{+} \mathrm{DCs}, \mathrm{K}^{+} \mathrm{LCs}$ and CBs. Several questions remain to be answered, such as: are the processes of $\mathrm{MN}$ formation reversible in the next cell division? Can $\mathrm{K}^{-}$ $\mathrm{MNi}$ transform into chromosome fragments and $\mathrm{CB}$, or $\mathrm{K}^{+} \mathrm{MNi}$ into $\mathrm{K}^{+} \mathrm{DC}, \mathrm{K}^{+} \mathrm{LC}$ and $\mathrm{CB}$, in mitosis?

The frequency of $\mathrm{CB}$ was not enhanced in mitosis of $\mathrm{K}^{-} \mathrm{MN}$ - and $\mathrm{K}^{+} \mathrm{MN}$-bearing cells compared to $\mathrm{MN}$-free cells (Figure 5). The data suggested that $\mathrm{K}^{-} \mathrm{MNi}$ and $\mathrm{K}^{+} \mathrm{MNi}$ were unlikely transformed into $\mathrm{CB}$ in mitosis, although $\mathrm{CBs}$ were one of main origins of $\mathrm{K}^{-} \mathrm{MNi}$ and $\mathrm{K}^{+} \mathrm{MNi}[12,13]$.

A recent study showed that chromosomes within $\mathrm{MNi}$ reincorporated into daughter nuclei at a significant frequency during mitosis $[19,20]$. In the study, $\mathrm{K}^{+} \mathrm{MN}$-bearing cells produced more $\mathrm{K}^{+} \mathrm{LCs}$ and $\mathrm{K}^{+} \mathrm{MNs}$ during mitosis than $\mathrm{MN}$-free cells. The results suggested that part of $\mathrm{K}^{+} \mathrm{MNi}$ may transform into $\mathrm{K}^{+} \mathrm{LCs}$ and $\mathrm{K}^{+} \mathrm{MNi}$. As there are spontaneous $\mathrm{K}^{+} \mathrm{LCs}$ and $\mathrm{K}^{+} \mathrm{MNi}$ in mitosis of MN-free HeLa cells, not all $\mathrm{K}^{+} \mathrm{LCs}$ or $\mathrm{K}^{+} \mathrm{MNi}$ resulted from $\mathrm{K}^{+} \mathrm{MNi}$ of mother cells. However, it is not likely that all $\mathrm{K}^{+} \mathrm{MNi}$ reincorporated into daughter nuclei, for defects of MN structure [20].

In contrast to $\mathrm{K}^{+} \mathrm{MNi}$, if chromosomal materials in $\mathrm{K}^{-} \mathrm{MNi}$ condense into chromosomal fragments during prophase, they are unlikely to return to main nuclei, and frequently evolve into $\mathrm{K}^{-} \mathrm{MNi}$ in daughter cells. Subsequently, the chromosomes in $\mathrm{K}^{+} \mathrm{MNi}$ may be able to reincorporate into main nuclei. The cycle of $\mathrm{K}^{-} \mathrm{MN} \rightarrow$ Chromosome fragment $\rightarrow \mathrm{K}^{-} \mathrm{MN}$ might occur during mitosis.

If this is the case, the more $\mathrm{K}^{-} \mathrm{MNi}$ cells bear, the more chromosome fragments and $\mathrm{K}^{-} \mathrm{MNi}$ emerge during mitosis and in daughter cells, respectively. In this study, there were five cells, each of which contained two $\mathrm{K}^{-} \mathrm{MNi}$. They produced eight chromosome fragments and transformed into seven $\mathrm{K}^{-} \mathrm{MNi}$ in six daughter cells (data not shown). In the present study, there were four cells which each carried both a $\mathrm{K}^{-} \mathrm{MN}$ and a $\mathrm{K}^{+} \mathrm{MN}$; these produced four chromosome fragments and one $\mathrm{K}^{+} \mathrm{LC}$ in mitosis, which further evolved into four $\mathrm{K}^{-} \mathrm{MNi}$ and one $\mathrm{K}^{+} \mathrm{MN}$ in daughter cells (data not shown). These results show different fates between $\mathrm{K}^{-} \mathrm{MN}$ and $\mathrm{K}^{+} \mathrm{MN}$ in the same cell and kinetochores determine the fates of $\mathrm{MNi}$.

Previous research indicated that the presence of micronuclei did 
Citation: Zhou X, Li D, Xie Z, Jiang E, Wei L, et al. (2018) The Cycle of Kinetochore-Negative Micronuclei and Chromosome Fragments Occurred in Mitosis of Hela Cells. Single Cell Biol 7: 172. doi:10.4172/2168-9431.1000172

not result in multi-polar mitosis [14]. We further observed that $\mathrm{K}^{-} \mathrm{MNi}$ or $\mathrm{K}^{+} \mathrm{MNi}$ did not increase multi-polar mitosis. The overwhelming majority of mitoses of $\mathrm{K}^{-} \mathrm{MN}$-bearing and $\mathrm{K}^{+} \mathrm{MN}$-bearing cells were bipolar, which was similar to $\mathrm{MN}$-free cells.

\section{Conclusion}

This study aimed to investigate the differences in the fates of $\mathrm{K}^{-} \mathrm{MNi}$ and $\mathrm{K}^{+} \mathrm{MNi}$ in mitosis. The results can be briefly summarized in the following points.

First, the presence of $\mathrm{K}^{-} \mathrm{MNi}$ and $\mathrm{K}^{+} \mathrm{MNi}$ did not result in multipolar mitosis. There were no differences in the polar number of mitosis in $\mathrm{K}^{-}$ $\mathrm{MN}$-bearing and $\mathrm{K}+\mathrm{MN}$-bearing cells. The overwhelming majority of mitoses were bipolar in both $\mathrm{K}^{-} \mathrm{MN}$-bearing and $\mathrm{K}^{+} \mathrm{MN}$-bearing cells. Similar results were found in MN-free cells.

Second, there are different fates between $\mathrm{K}^{-} \mathrm{MNi}$ and $\mathrm{K}^{+} \mathrm{MNi}$ in mitosis. There were obvious differences in the production of abnormal chromosomes and $\mathrm{MNi}$ during mitosis in $\mathrm{K}^{-} \mathrm{MN}$-bearing and $\mathrm{K}^{+} \mathrm{MN}$-bearing cells. The $\mathrm{K}^{-} \mathrm{MN}$-bearing cells produced much more chromosome fragments and $\mathrm{K}^{-} \mathrm{MNi}$ during mitosis than did $\mathrm{MN}$ free cells. However, the $\mathrm{K}^{+} \mathrm{MN}$-bearing cells formed more $\mathrm{K}^{+} \mathrm{LCs}$ and $\mathrm{K}^{+} \mathrm{MNi}$ than did $\mathrm{MN}$-free cells. The chromosomes in $\mathrm{K}^{+} \mathrm{MNi}$ might reincorporate into the main nucleus, while $\mathrm{K}^{-} \mathrm{MNi}$ may be involved in the cycle of $\mathrm{K}^{-} \mathrm{MN} \rightarrow$ chromosome fragment $\rightarrow \mathrm{K}^{-} \mathrm{MN}$.

\section{Declaration}

\section{Ethics approval and consent to participate}

Not applicable.

\section{Competing Interests}

The authors declare that they have no competing interests.

\section{Funding}

This work was supported by the Key Project of Natural Science Foundation of the Anhui Provincial Education Department (Grant number 03087060 to ZX); Natural Science Foundation of the Anhui Provincial Education Department (Grant number 2013A110 to EJ); Foundation of Anhui Provincial Key Disciplines of Biology (Grant number 2014JXJS002, 2014SKQJ016 to EJ), and Anhui Agricultural University Foundation for Stability and Introduction of Talent. Funding for open access charge: Key Project of Natural Science Foundation of the Anhui Provincial Education Department.

\section{Authors' contributions}

ZX designed the methods and experiments, analyzed the results, and drafted the manuscript. EJ designed the methods and experiments, analyzed the results, and drafted the manuscript. LW designed the methods and experiments, performed live-cell imaging assays, and analyzed the results. FT performed livecell imaging assays and analyzed the results. MY and SW contributed to designing the experiments and analyzed the results. XZ and LD contributed to revising the article. All authors read and approved the final manuscript.

\section{Acknowledgements}

We appreciate Professor Qinghua Shi for generous help in this research. We also thank Dr. Yun Huang and Dr. Long Jiang for excellent technical assistance.

\section{References}

1. Tweats DJ, Johnson GE, Scandale I, Whitwell J, Evans DB, et al. (2016)
Genotoxicity of flubendazole and its metabolites in vitro and the impact of a new formulation on in vivo aneugenicity. Mutagenesis 31: 309-321.

2. Tewari S, Khan K, Husain N, Rastogi M, Mishra SP, et al. (2016) Periphera blood lymphocytes as in vitro model to evaluate genomic instability caused by low dose radiation. Asian Pac J Cancer Prev 17: 1773-1777.

3. Souza LD, Da Cruz LA, Cerqueira EM, Meireles J (2016) Micronucleus as biomarkers of cancer risk in anabolic androgenic steroids users. Hum. Exp. Toxicol 36: 302-310.

4. Schupp N, Stopper H, Heidland A (2016) DNA damage in Chronic kidney disease: Evaluation of clinical biomarkers. Oxid Med Cell Longev 2: 1.

5. Chan GK, Liu ST, Yen TJ (2005) Kinetochore structure and function. Trends Cell Biol 15: 589-598.

6. Nagpal H, Fukagawa T (2016) Kinetochore assembly and function through the cell cycle. Chromosoma 125: 645-659.

7. Ding GR, Nakahara T, Miyakoshi J (2003) Induction of kinetochore-positive and kinetochore-negative micronuclei in $\mathrm{CHO}$ cells by ELF magnetic fields and/or X-rays. Mutagenesis 18: 439-443.

8. Mattiuzzo M, Fiore M, Ricordy R, Degrassi F (2006) Aneuploidy-inducing capacity of two widely used pesticides. Carcinogenesis 27: 2511-2518.

9. Benameur L, Orsière $T$, Rose J, Botta A (2011) Detection of environmental clastogens and aneugens in human fibroblasts by cytokinesis-blocked micronucleus assay associated with immunofluorescent staining of CENP-A in micronuclei. Chemosphere 5: 676-680.

10. Vuong MC, Hasegawa LS, Eastmond DA (2013) A comparative study of the cytotoxic and genotoxic effects of ICRF-154 and bimolane, two catalytic inhibitors of topoisomerase II. Mutat Res 750: 63-71.

11. Roy S, Kulkarni R, Hewitt NJ, Aardema MJ (2016) The epiderm ${ }^{\mathrm{TM}} 3 \mathrm{D}$ human reconstructed skin micronucleus (RSMN) assay: Historical control data and proof of principle studies for mechanistic assay adaptations. Mutat Res 805 25-37.

12. Jiang $E$ (2016) Differences in the origins of kinetochore-positive and kinetochore-negative micronuclei: A live cell imaging study. Mutat Res 787 : 7-14.

13. Rao X, Zhang Y, Yi Q, Hou H, Xu B, et al. (2008) Multiple origins of spontaneously arising micronuclei in HeLa cells: Direct evidence from longterm live cell imaging. Mutat Res 646: 41-49.

14. Utani K, Kohno Y, Okamoto A, Shimizu N (2010) Emergence of micronuclei and their effects on the fate of cells under replication stress. PLoS One 5: e10089.

15. Yasui M, Koyama N, Koizumi T, Senda-Murata K, Takashima Y, et al. (2010) Live cell imaging of micronucleus formation and development. Mutat Res 692 12-18.

16. Huang $Y$, Hou H, Yi Q, Zhang Y, Chen D, et al. (2011) The fate of micro nucleated cells post $X$-irradiation detected by live cell imaging. DNA Repair (Amst) 10: 629-638.

17. Terradas $M$, Martín M, Genescà A (2016) Impaired nuclear functions in micronuclei results in genome instability and chromothripsis. Arch Toxicol 90 2657-2667.

18. Hatch EM, Fischer AH, Deerinck TJ, Hetzer MW (2013) Catastrophic nuclear envelope collapse in cancer cell micronuclei. Cell 154: 47-60.

19. Crasta K, Ganem NJ, Dagher R, Lantermann AB, Ivanova EV, et al. (2012) DNA breaks and chromosome pulverization from errors in mitosis. Nature 482 : $53-58$

20. Zhang CZ, Spektor A, Cornils H, Francis JM, Jackson EK, et al. (2015) Chromothripsis from DNA damage in micronuclei. Nature 522: 179-184. 